Article

\title{
Storage and Climatic Controlling Factors of Litter Standing Crop Carbon in the Shrublands of the Tibetan Plateau
}

\author{
Xiuqing Nie ${ }^{1,2,3}$, Dong Wang ${ }^{1,3}$, Lucun Yang ${ }^{2,4}$ and Guoying Zhou ${ }^{2,4, *(\mathbb{C})}$ \\ 1 Key Laboratory of Tree Breeding and Cultivation of the State Forestry Administration, \\ Research Institute of Forestry, Chinese Academy of Forestry, Beijing 100091, China; \\ niexiuqing123@163.com (X.N.); dwang@caf.ac.cn (D.W.) \\ 2 Key Laboratory of Tibetan Medicine Research, Northwest Institute of Plateau Biology, \\ Chinese Academy of Science, Xining 810008, China; Yanglucun@nwipb.cas.cn \\ 3 Research Institute of nature protected Area, Chinese Academy of Forestry, Beijing 100091, China \\ 4 Qinghai Key Laboratory of Qing-Tibet Biological Resources, Xining 810008, China \\ * Correspondence: zhougy@nwipb.cas.cn; Tel.: +86-971-6159630; Fax: +86-971-6143282
}

Received: 17 September 2019; Accepted: 4 November 2019; Published: 5 November 2019

\begin{abstract}
Litter is an important component of terrestrial ecosystems and plays a significant role in carbon cycles. Quantifying regional-scale patterns of litter standing crop distribution will improve our understanding of the mechanisms of the terrestrial carbon cycle, and thus enable accurate predictions of the responses of the terrestrial carbon cycle to future climate change. In this study, we aimed to estimate the storage and climatic controlling factors of litter standing crop carbon in the Tibetan Plateau shrublands. We investigated litter standing crop carbon storage and its controlling factors, using a litter survey at 65 shrublands sites across the Tibetan Plateau from 2011-2013. Ordinary least squares regression analyses were conducted to estimate the relationships between litter standing crop carbon, longitude, and latitude. Multiple linear regressions were used to evaluate relationships among litter standing crop carbon, mean annual temperature (MAT), mean annual precipitation (MAP), and aboveground biomass. The litter standing crop carbon storage was $10.93 \mathrm{Tg} C, 7.40 \mathrm{Tg} \mathrm{C}$, and $3.53 \mathrm{Tg} \mathrm{C}$ in desert shrublands and alpine shrublands, respectively. Litter standing crop carbon decreased with longitude, and was stable with increasing latitude. Most (80\%) of the litter standing crop was stored in branches, with only $20 \%$ stored in foliage in the shrublands on the Tibetan Plateau. The conversion coefficient was 0.44 for litter standing crop to litter standing crop carbon, and 0.39 and 0.45 for foliage and branch litter standing crop to foliage and branch litter standing crop carbon, respectively. Aboveground biomass can accelerate more inputs of litter and has a positive effect on litter standing crop carbon. MAT had a positive effect on litter standing crop carbon due to stimulating more input of aboveground biomass. However, MAP had a negative relationship with litter standing crop carbon by enhancing litter decomposition.
\end{abstract}

Keywords: litter standing crop carbon; conversion coefficient; climatic factors; Tibetan Plateau; shrublands

\section{Introduction}

Litter is an important component of terrestrial ecosystems. Its production and accumulation contribute to carbon sequestration and soil fertility [1]. The litter standing crop depends on the rates of litter production and litter decomposition. If the litter production rate is greater than the litter decomposition rate, litter becomes a sink of atmosphere $\mathrm{CO}_{2}$; if the litter decomposition rate is greater than the litter production rate, it becomes a carbon source [2]. Although soil acts as the largest carbon 
pool [3], the litter standing crop pool also accounts for a non-ignorable amount of emissions; the global litter standing crop carbon pool has been estimated to be $43 \mathrm{Pg} \mathrm{C}$ for all forest ecosystem carbon stocks [4], and the litter standing crop carbon pool in both forest and grassland ecosystems in China has been estimated as being $0.52 \mathrm{Pg} \mathrm{C}[5]$, which means litter plays a significant role in carbon cycles $[1,6,7]$. Most researchers have focused on litter production and litter decomposition [8,9], while few studies have considered litter standing crop carbon in shrublands [2], especially on the Tibetan Plateau.

As a result of global climatic changes, the Tibetan Plateau has been experiencing warming, and the mean annual temperature (MAT) has increased by $0.05^{\circ} \mathrm{C}$ every year [10]. Meanwhile the mean annual precipitation (MAP) has increased by $10.2 \mathrm{~mm}$ every ten years [10]. Furthermore, climatic conditions, such as changes in precipitation and temperature, are predicted to not only continue, but also perhaps to accelerate in the future [11,12]. It has been demonstrated that climatic factors such as MAP and MAT greatly affect litter standing crop carbon [5]. Climatic factors also indirectly influence litter decomposition through their effects on biotic factors [2]. It has been demonstrated that MAT and MAP have positive effects on litter production in forests in China [13]. At the regional scale, a similar trend was observed in Tiantong national forest park [14]. However, other studies have indicated that litter production in northeastern China's forests is influenced by temperature, but not significantly affected by precipitation [15]. Therefore, the effects of climatic factors on litter production remain uncertain. Compared with climatic effects on litter production, its effects on litter standing crop have been less researched in the shrublands on the Tibetan Plateau.

The conversion coefficient of litter standing crop to litter standing crop carbon is an important parameter in the carbon budget [16]. Generally, researchers have used 0.50 to convert biomass to biomass carbon [17]. However, the parameter of 0.50 overestimated carbon by $22 \%$ when estimating the litter carbon budget in shrublands across south China [16]. Furthermore, different components play important roles in shaping the magnitude of the conversion coefficient [18]. Although the conversion coefficient of litter standing crop to litter standing crop carbon has been estimated in shrublands of southern China [16], components such as foliage and branch standing crop to foliage and branch standing crop carbon have not been considered. Furthermore, although biomass and soil organic carbon have been explored in the Tibetan Plateau shrublands [19-21], it was difficult to assess the total carbon storage in shrublands ecosystem without litter standing crop carbon. It has been demonstrated that the biophysical processes that control soil carbon on the Tibetan Plateau may differ from those in other regions [20,22]. We hypothesized that the conversion coefficient in the Tibetan Plateau shrublands was different from that in the southern China shrublands. We also aimed to explore the litter standing crop carbon responses to changes of MAT, MAP and aboveground biomass in the shrublands on the Tibetan Plateau.

\section{Materials and Methods}

\subsection{Study Area}

This study investigated shrublands on the northeastern Tibetan Plateau (Figure 1). Shrublands are one of the most widely distributed ecosystems on the plateau [23]. Shrublands compose woody vegetation, with coverage of more than $30 \%$ and a mean height below $5 \mathrm{~m} \mathrm{[24]} \mathrm{and} \mathrm{are} \mathrm{primarily}$ classified as desert shrublands or alpine shrublands [23]. Desert shrublands are mostly distributed in drier areas, such as the Qaidam Basin, and are characterized by species that can endure severe drought, such as Kalidium foliatum (Pall.) Moq, Salsola abrotanoides Bunge, and Sympegma regelii Bunge. Compared with alpine shrublands, only a few types of super-xerophytic herbs grow in desert shrublands. Brown desert soil and grey brown desert soil are mainly soil types in desert shrublands ecosystems, while soil in desert shrublands is very thin and more infertile than that in alpine shrublands [23]. In contrast, alpine shrublands are located in mountains with a cold and semiarid environment. Chestnut soil, grey cinnamon soil, and alpine shrubby meadow soil are mainly soil types in alpine shrublands ecosystems [23]. Representative species include Rhododendron thymifolium Maxim, R. capitatum Maxim, 
and Sibiraea laevigata (Linn.) Maxim. Mesophyte herbs, including Kobresia spp., Carex spp., and Oxytropis spp., are located in alpine desertblands. MAP and MAT in the study regions range from 17.6 to $764.4 \mathrm{~mm}$ and -5.6 to $8.9^{\circ} \mathrm{C}$, respectively [25].



Figure 1. Distribution of 65 sampling sites in the shrublands of the Tibetan Plateau, which was based on the vegetation of China (1:100 0000) [26].

\subsection{Field Investigation and Laboratory Measurements}

In line with China's vegetation atlas (1:1000000) [26] and field investigations, we systematically selected 195 plots in 65 sites across the northeastern Tibetan Plateau shrublands in July and August from 2011 to 2013 (Figure 1). We selected three plots $(1 \mathrm{~m} \times 1 \mathrm{~m})$ at each site and the distance of two plots was between $5 \mathrm{~m}$ and $50 \mathrm{~m}$. At each site, all of the litter, including older litter and decomposed litter in the three plots, was collected to determine the litter standing crop [27]. Also, all shrubland plants in three plots were harvested to measure aboveground biomass. The samples of litter and aboveground biomass were oven dried at $65{ }^{\circ} \mathrm{C}$ to a constant weight, and weighed to the nearest $0.01 \mathrm{~g}$. The litters were primarily foliage or branches. Carbon content of litter was determined using an elemental analyzer (2400 II CHNS; Perkin-Elmer, Boston, MA, USA).

\subsection{Climate Data}

To investigate the potential effects of climate factors on the litter standing crop carbon, MAT and MAP were extracted for each site from the WorldClim database (http://www.Worldclim.org/) with a spatial resolution of $1 \times 1 \mathrm{~km}^{2}[28,29]$.

\subsection{Data Analysis}

Ordinary least squares regression analyses were used to estimate the relationships between litter standing crop carbon, longitude, and latitude. Multiple linear regressions were conducted to evaluate relationships among litter standing crop carbon, MAT, MAP, and aboveground biomass. All analyses were conducted using SPSS 22.0 (SPSS Inc., Chicago, USA). Graphs were created in SigmaPlot 12.5 (Systat Software, Inc., Point Richmond, CA, USA). 


\section{Results}

\subsection{Size and Storage of Litter Standing Crop in Tibetan Plateau Shrublands}

The litter standing crop ranged from $0.04 \mathrm{~kg} \mathrm{~m}^{-2}$ to $0.48 \mathrm{~kg} \mathrm{~m}^{-2}$. The branch standing crop ranged from $0.02 \mathrm{~kg} \mathrm{~m}^{-2}$ to $0.48 \mathrm{~kg} \mathrm{~m}^{-2}$, and foliage was no more than $0.25 \mathrm{~kg} \mathrm{~m}^{-2}$. The mean litter standing crop was $0.23 \mathrm{~kg} \mathrm{~m}^{-2}$ in the shrublands overall (Table 1), and it was $0.25 \mathrm{~kg} \mathrm{~m}^{-2}$ and $0.19 \mathrm{~kg} \mathrm{~m}^{-2}$ in desert shrublands and alpine shrublands, respectively (Table 1). The mean values for foliage and branch standing crops in the shrublands were $0.04 \mathrm{~kg} \mathrm{~m}^{-2}$, and $0.19 \mathrm{~kg} \mathrm{~m}^{-2}$, respectively (Table 1). Most litter standing crop was stored in the branch standing crop, accounting for $80 \%$ of all litter standing crop overall (Figure $2 \mathrm{a}$ ), and $76 \%$ and $87 \%$ in alpine shrublands and desert shrublands, respectively (Figure 2b,c).

Table 1. Size, storage and carbon storage of foliage, branch, and litter standing crops in the shrublands of the Tibetan Plateau.

\begin{tabular}{|c|c|c|c|c|c|c|c|c|c|c|}
\hline \multirow{2}{*}{$\begin{array}{l}\text { Shrubland } \\
\text { Type }\end{array}$} & \multirow{2}{*}{$\begin{array}{c}\text { Area } \\
\left(10^{4} \mathrm{~km}^{2}\right)\end{array}$} & \multicolumn{3}{|c|}{$\begin{array}{l}\text { Litter Standing Crop } \\
\text { Density }\left(\mathrm{kg} \mathrm{m}^{-2}\right)\end{array}$} & \multicolumn{3}{|c|}{$\begin{array}{l}\text { Litter Standing Crop } \\
\text { Storage (Tg) }\end{array}$} & \multicolumn{3}{|c|}{$\begin{array}{l}\text { Litter Standing Crop } \\
\text { Carbon Storage (Tg C) }\end{array}$} \\
\hline & & Foliage & Branch & Litter & Foliage & Branch & Litter & Foliage & Branch & Litter \\
\hline $\begin{array}{c}\text { Desert } \\
\text { shrublands }\end{array}$ & 6.69 & 0.03 & 0.22 & 0.25 & 2.11 & 14.63 & 16.74 & 0.82 & 6.58 & 7.40 \\
\hline $\begin{array}{c}\text { Alpine } \\
\text { shrublands }\end{array}$ & 4.29 & 0.05 & 0.14 & 0.19 & 1.94 & 6.15 & 8.09 & 0.76 & 2.77 & 3.53 \\
\hline Overall & 10.98 & 0.04 & 0.19 & 0.23 & 4.05 & 20.78 & 24.83 & 1.58 & 9.35 & 10.93 \\
\hline
\end{tabular}
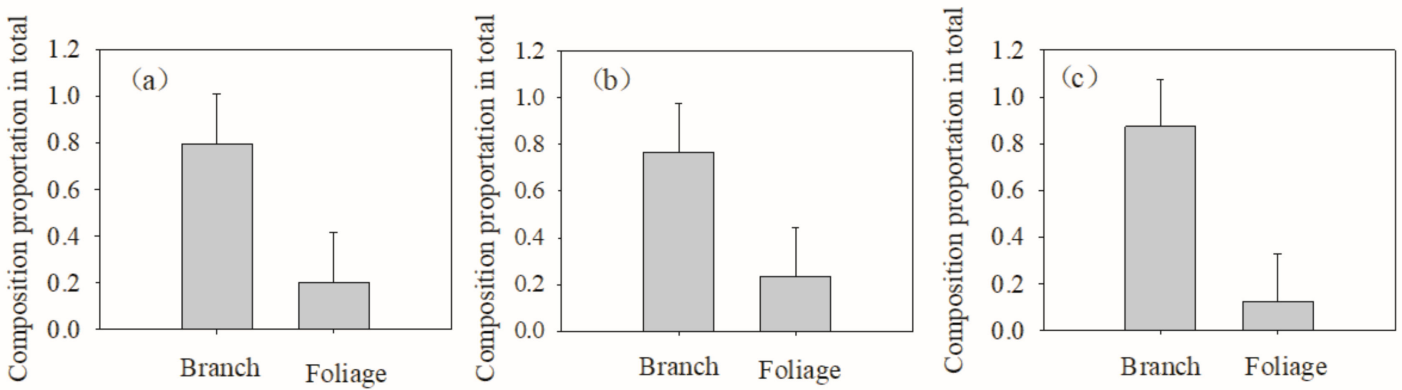

Figure 2. The proportions of branch and foliage standing crop in the litter standing crop on the Tibetan Plateau, (a) all shrublands, (b) alpine shrublands, (c) desert shrublands.

Overall, the litter standing crop storage in the shrublands was $24.83 \mathrm{Tg} ; 16.74 \mathrm{Tg}$ and $8.09 \mathrm{Tg}$ in desert shrublands and alpine shrublands, respectively. Storages in the foliage and branch standing crops were $4.05 \mathrm{Tg}$ and $20.78 \mathrm{Tg}$, respectively (Table 1 ).

\subsection{Conversion Coefficient, Storage, and Distribution of Litter Standing Crop Carbon}

The conversion coefficient of litter standing crop to litter standing crop carbon was 0.44 in the shrublands of the Tibetan Plateau, which supported our hypothesis that the conversion coefficient was different from that in the shrublands of southern China. The conversion coefficients for foliage and branch standing crop to foliage and branch standing crop carbon were 0.39 and 0.45 , respectively. Litter standing crop carbon was $10.93 \mathrm{Tg} \mathrm{C}$ in the northeastern Tibetan Plateau shrublands, and they were $7.40 \mathrm{Tg} C$ and $3.53 \mathrm{Tg} C$ in desert shrublands and alpine shrublands, respectively (Table 1). Furthermore, the conversion coefficients of branch standing crop to branch standing crop carbon were 0.42 and 0.46 in desert shrublands and alpine shrublands, respectively. Meanwhile, the conversion coefficients of foliage standing crop to foliage standing crop carbon were 0.27 and 0.40 in desert shrublands and alpine shrublands, respectively. 
Spatially, the litter standing crop carbon was stable with increased latitude (Figure 3a), but it decreased with longitude in total shrublands (Figure 3b). Similarly, the significant trend also existed in the alpine shrublands (Figure 3c). In the desert shrublands, the range of longitude was between $94.51^{\circ}$ and $98.73^{\circ}$. The litter standing crop carbon has a decreasing trend with an increasing longitude in desert shrublands (Figure 3d). Specifically, the highest litter standing crop carbon was in a low longitude $\left(94.51^{\circ}-95.91^{\circ}\right)$, while the lowest litter standing crop carbon was in high MAT $\left(97.32^{\circ}-98.73^{\circ}\right)$. In medium MAT $\left(95.91^{\circ}-97.32^{\circ}\right)$, the litter standing crop carbon was moderate (Figure $3 \mathrm{~d}$ ).
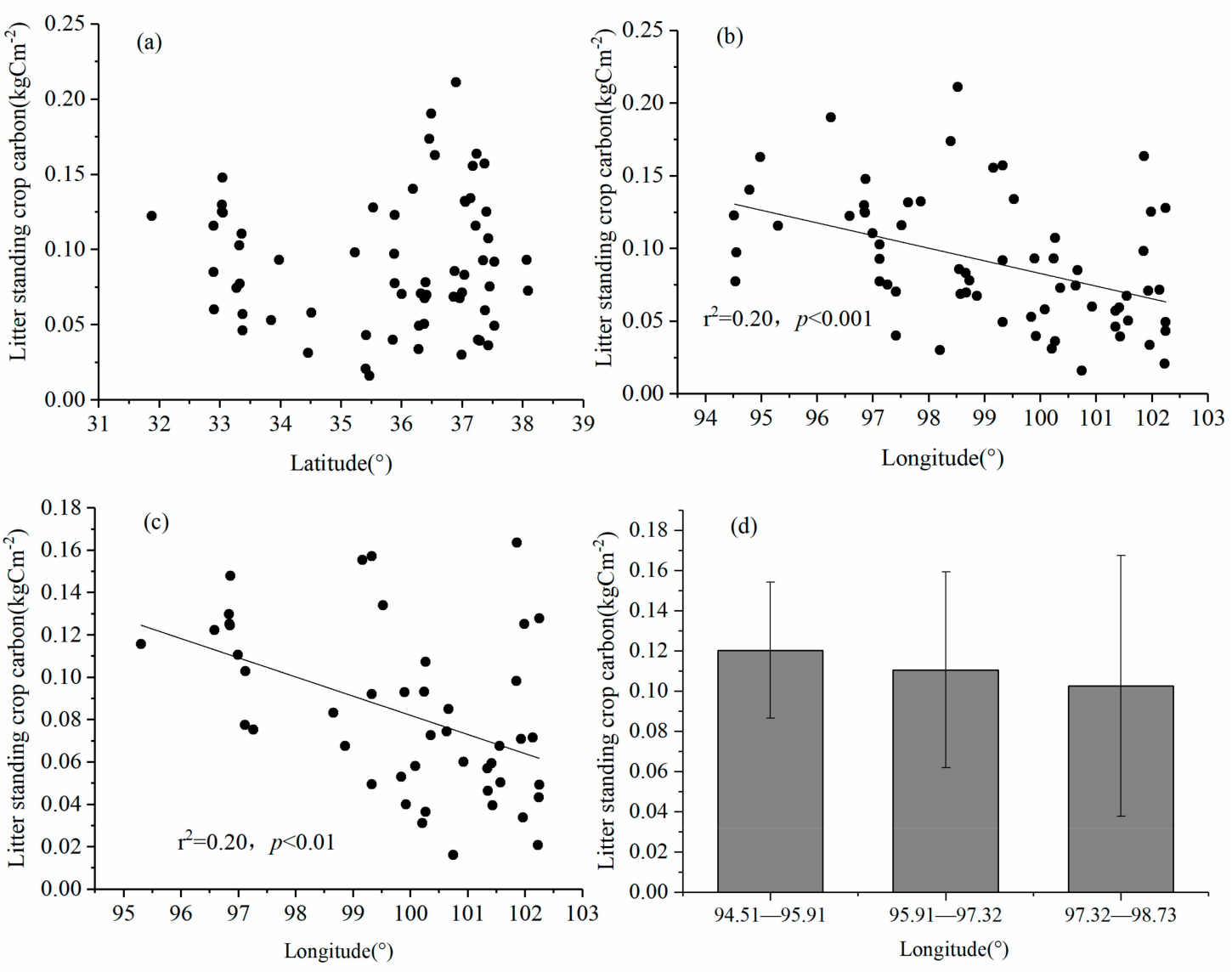

Figure 3. Relationships between litter standing crop carbon and latitude and longitude, (a) and (b) total shrublands, (c) alpine shrublands, (d) desert shrublands.

\subsection{Effects of MAP and MAT on Litter Standing Crop Carbon}

Litter standing crop carbon significantly decreased with MAP (Figure 4a) $(p<0.01)$. In the alpine shrublands, the range of MAP was between $160.83 \mathrm{~mm}$ and $572.50 \mathrm{~mm}$. The litter standing crop carbon showed a negative trend with MAP in alpine shrublands. Specifically, the highest litter standing crop carbon was in low MAP (160.83 mm-298.06 mm), while the lowest litter standing crop carbon in high MAP (435.28-572.50 mm), and in medium MAP (298.06 mm-435.28 mm), the litter standing crop carbon was moderate (Figure 4b). Similarly, and the range of MAP was between $35.83 \mathrm{~mm}$ and $265.00 \mathrm{~mm}$ in desert shrublands. The highest litter standing crop carbon was in low MAP (35.83 mm-112.22 mm), while the lowest litter standing crop carbon in high MAP (188.61 mm-265.00 mm), and in medium MAP (112.22 mm-188.61 mm), the litter standing crop carbon was moderate (Figure 4c).

Litter standing crop carbon increased with MAT $(p<0.01)$ (Figure $4 d)$. In the alpine shrublands, the range of MAT was between $-2.83^{\circ} \mathrm{C}$ and $3.20^{\circ} \mathrm{C}$. The litter standing crop carbon showed a positive trend with MAT in alpine shrublands. Specifically, the highest litter standing crop carbon was in high $\operatorname{MAT}\left(1.18^{\circ} \mathrm{C}-3.20^{\circ} \mathrm{C}\right)$, while the lowest litter standing crop carbon in low $\operatorname{MAT}\left(-2.85^{\circ} \mathrm{C}--0.83^{\circ} \mathrm{C}\right)$, and in medium MAT $\left(-0.83^{\circ} \mathrm{C}-1.18^{\circ} \mathrm{C}\right)$, the litter standing crop carbon was moderate (Figure $\left.4 \mathrm{e}\right)$. 
Similarly to desert shrublands, and the range of MAT was between $-1.14{ }^{\circ} \mathrm{C}$ and $5.47^{\circ} \mathrm{C}$. The litter standing crop carbon showed a positive trend with MAT in desert shrublands. Specifically, the highest litter standing crop carbon was in high MAT $\left(3.65^{\circ} \mathrm{C}-5.47^{\circ} \mathrm{C}\right)$, while the lowest litter standing crop carbon was in low MAT $\left(-1.14{ }^{\circ} \mathrm{C}-0.42{ }^{\circ} \mathrm{C}\right)$, and in medium MAP $\left(0.42{ }^{\circ} \mathrm{C}-3.65{ }^{\circ} \mathrm{C}\right)$, the litter standing crop carbon was moderate (Figure $4 \mathrm{f}$ ). Generally, multiple linear regressions showed that in total shrublands, litter standing crop carbon $=-0.001 \mathrm{MAP}+0.01 \mathrm{MAT}+0.25(r=0.40, p<0.01)$.
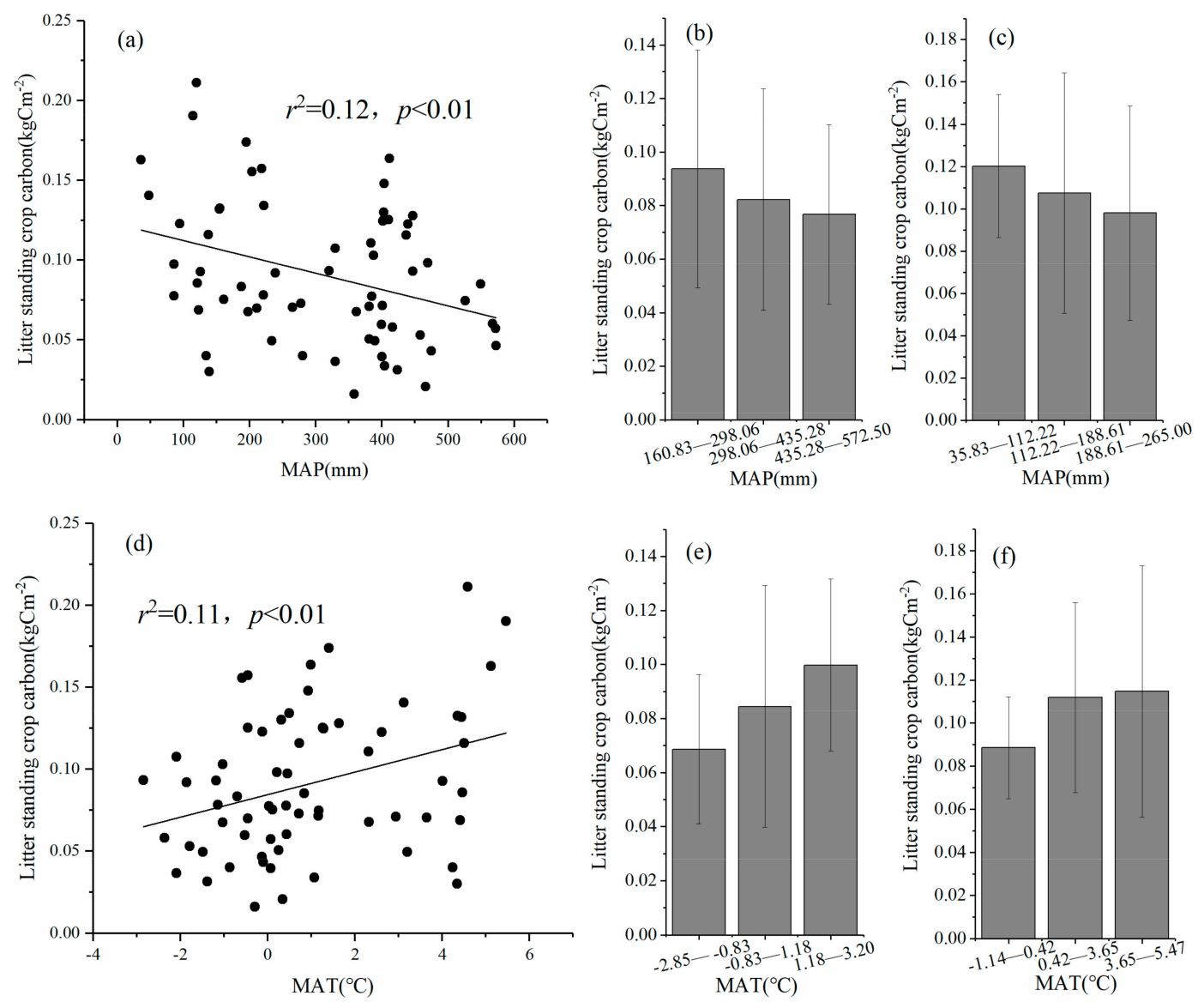

Figure 4. Relationships among mean annual precipitation (MAP) and mean annual temperature (MAT) and litter standing crop carbon, $(\mathbf{a}, \mathbf{d})$ total shrublands, $(\mathbf{b}, \mathbf{e})$ alpine shrublands, $(\mathbf{c}, \mathbf{f})$ desert shrublands.

\subsection{Effects of Aboveground Biomass and Climatic Factors on Litter Standing Crop Carbon}

Increasing aboveground biomass can stimulate litter standing crop carbon (Figure 5a) $(p<0.01)$, specifically, the positive trend also existed in both alpine shrublands and desert shrublands (Figure $5 b$ ). Generally, multiple linear regressions showed that litter standing crop carbon $=-0.001 \mathrm{MAP}+0.01$ MAT +0.0001 Aboveground biomass $+0.11(r=0.42, p<0.01)$. Furthermore, the relationships among litter standing crop carbon, aboveground biomass, MAT, and MAP were shown in Figure S1. 

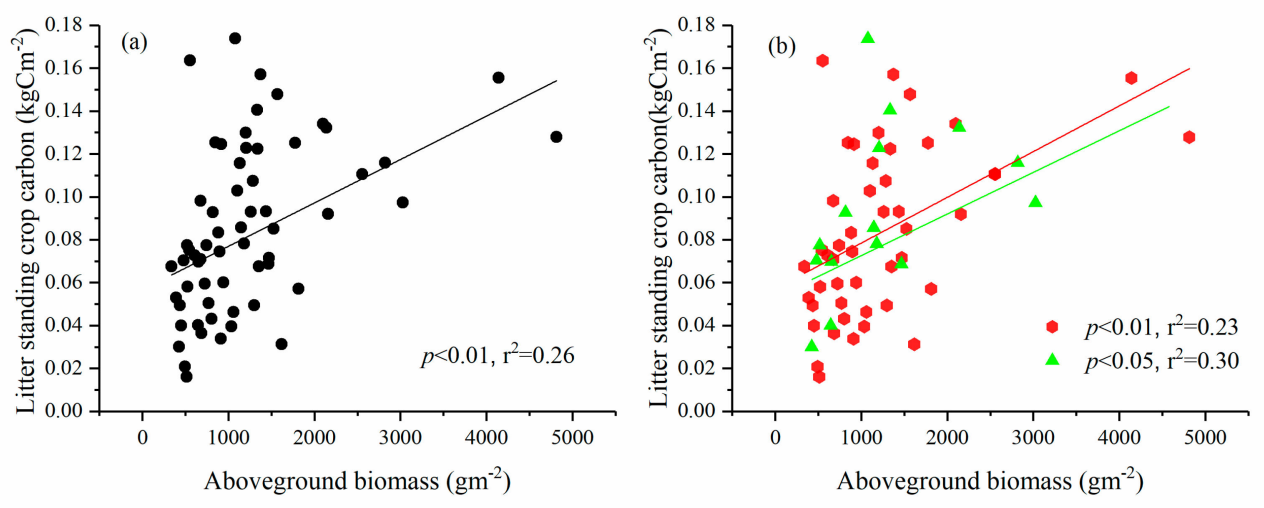

Figure 5. Relationships between aboveground biomass and litter standing crop carbon, (a) total shrublands, (b) red circle means alpine shrublands, green triangle means desert shrublands.

\section{Discussion}

\subsection{Size of Litter Standing Crop}

The density of the litter standing crop in the Tibetan Plateau shrublands was $0.23 \mathrm{~kg} \mathrm{~m}^{-2}$, nearly half of the litter standing crop in the forests $\left(0.45 \mathrm{~kg} \mathrm{~m}^{-2}\right)$ of the Tibetan Plateau [5], and was more than three times as much as the litter standing crop of the grasslands $\left(0.05 \mathrm{~kg} \mathrm{~m}^{-2}\right)$ of the Tibetan Plateau [5]. The mean aboveground biomass in the shrublands was $1.10 \mathrm{~kg} \mathrm{~m}^{-2}$ [19], less than that of $4.22 \mathrm{~kg} \mathrm{~m}^{-2}$ in the forests [30], and greater than that of $0.08 \mathrm{~kg} \mathrm{~m}^{-2}$ in the grasslands of the plateau [31]. As aboveground biomass made the greatest contribution to litter standing crop in ecosystem [1], the litter standing crop in shrublands was in the range between forest and grasslands.

The litter standing crop in the shrublands of south China was $0.32 \mathrm{~kg} \mathrm{~m}^{-2}$ [16], larger than our result of $0.23 \mathrm{~kg} \mathrm{~m}^{-2}$ for the Tibetan Plateau. This difference may result from the greater amount of aboveground biomass in the shrublands across south China, compared to the Tibetan Plateau shrublands. Aboveground biomass can shape the input resource of litter standing crop [1] and significantly accumulate litter standing crop. It has been demonstrated that aboveground biomass in shrublands in the south region of China was $1.44 \mathrm{~kg} \mathrm{~m}^{-2}$ [32], greater than the $1.10 \mathrm{~kg} \mathrm{~m}^{-2}$ of the Tibetan Plateau shrublands [19].

\subsection{Controlling Factors of Litter Standing Crop Carbon}

Climatic factors can significantly shape litter standing crop [33,34]. Generally, precipitation not only stimulates vegetation growth in arid regions [35], and furthermore increases input of litter standing crop, but also affects the leaching of chemical substances from litter and consequently limits the litter decomposition rate [2]. So precipitation has been shown to have a positive effect on litter production [13] and stimulates accumulation of litter standing crop. However, precipitation has restrained effects on accumulation of litter standing crop carbon in the Tibetan Plateau shrublands. This result was different from those for other regions and biomes. For forests, precipitation did not have a significant effect on litter standing crop in forests of the eastern Inner Mongolia Plateau [18] or forests in China [5]. Litter standing crop carbon was stable with increasing precipitation in southern regions of China shrublands [16]. It should be noted that precipitation can also enhance litter decomposition by maximizing decomposer activity $[11,36]$, which can reduce litter standing crop storage. Litter production and litter decomposition determine litter standing crop [37]. The restrain effects on the accumulation of litter standing crop carbon from precipitation may exceed the positive effects; consequently, increasing MAP decreases litter standing crop carbon in the shrublands, both alpine shrublands and desert shrublands, on the Tibetan Plateau.

Temperature is considered to be the most significant factor determining litter decomposition [38,39]. Rising temperature increases the litter decomposition rate [2]. In our study, MAT contributed to 
the accumulation of litter standing crop carbon in the shrublands on the Tibetan Plateau, which was different from other reported findings, specifically, that temperature had negative effects on accumulation of litter standing crop carbon in shrubland ecosystems in southern China [15] and in forests in China [5], whereas temperature was not a significant controlling factor for litter standing crop carbon in grasslands in China [5]. One of the most significant climate characteristics on the Tibetan Plateau is cold, and in the Tibetan Plateau shrublands, increasing temperature has been shown to play a significant role in shaping the amount of aboveground biomass [40]. Temperature contributes to the accumulation of aboveground biomass [40], which shapes amount of litter input, and stimulates more inputs into the litter standing crop; consequently, the litter standing crop in the shrublands of the Tibetan Plateau shows an increasing trend with MAT.

The climatic controlling factors on the litter standing crop carbon in the Tibetan Plateau shrublands, such as MAT and MAP, were different from those in other regions, which may indicate that the biophysical processes that control carbon on the Tibetan Plateau may differ from those in other regions [20,22]. In the global warming scenario, MAT is increasing by $0.05{ }^{\circ} \mathrm{C}$ every year $[10,41]$, which, combined with the positive relationship between litter standing crop carbon and temperature, contributes to the carbon sink trend in the Tibetan Plateau shrublands.

\subsection{Distribution and Conversion Coefficient of Litter Standing Crop to Litter Standing Crop Carbon}

Spatially, the litter standing crop carbon decreased with longitude in shrublands, which may result from climatic changes with different regions. With an increasing longitude, the MAP has an increasing trend (Figure S2a), and consequently, increasing precipitation limited accumulation of litter standing crop carbon (Figure $4 \mathrm{a}-\mathrm{c}$ ). At the same time, MAT has a decreasing trend with longitude (Figure S2b), and decreasing temperature also limited the accumulation of litter standing crop carbon (Figure $4 \mathrm{~d}-\mathrm{e}$ ). The climatic changes with longitude can explain the distribution of litter standing crop carbon in shrublands on the Tibetan Plateau.

It has been estimated that the conversion coefficient for litter standing crop to litter standing crop carbon is 0.41 in the shrublands of southern China [16], which is lower than our result of 0.44 . Different vegetation types result in various rates of litter production and litter decomposition due to climatic conditions [33,34], and eventually, shape the conversion coefficient for litter standing crop to litter standing crop carbon. Cold weather is the most significant climatic characteristics of the Tibetan Plateau [42], due to its high elevation. On the one hand, lower temperature suppresses decomposer activity [11,43], which contributes to the weak decomposition of litter on the Tibetan Plateau. On the other hand, plants tend to produce organic matter with a higher carbon content [44-46]. Therefore, the conversion coefficient for litter standing crop to litter standing crop carbon in shrublands was smaller on the Tibetan Plateau compared with in shrublands of southern China. Researchers use a coefficient of 0.50 to convert biomass to biomass carbon in woody ecosystems such as forests [47,48] and shrublands [17], while the coefficient is smaller $(0.45)$ in herbaceous ecosystems such as grasslands $[49,50]$. Our results reveal that the conversion coefficient for branch standing crop to branch standing crop carbon was 0.45 , larger than the conversion coefficient of 0.36 for foliage standing crop to foliage standing crop carbon, which indicates that the conversion coefficient in woody ecosystems is larger than in herbaceous ecosystems. Studies of forest and grassland ecosystem support this trend, with a conversion coefficient of 0.46 in forests and 0.40 in grasslands in China [5]. Therefore, it is better to use specific conversion coefficients for different ecosystems to estimate litter standing crop carbon. Furthermore, even with in the same ecosystem, such as shrublands, it is better to use a specific parameter to assess carbon pools, specifically, 0.41 for the shrublands of southern China [16] and 0.44 for the Tibetan Plateau shrublands. To conduct a more accurate estimation of the carbon pool, it is necessary to use conversion coefficients for the different components of litter standing crop (in this case, 0.45 and 0.36 , respectively, for branch and foliage standing crop in the shrublands of the Tibetan Plateau). Meanwhile, in the Tibetan Plateau, conversion coefficients of branch standing crop to branch standing crop carbon and foliage standing crop to foliage standing crop carbon were 0.46 and 0.42 , 
0.40, and 0.27 greater in alpine shrublands than in desert shrublands, respectively, which furthermore means that in the neighborhood regions (such as the Tibetan Plateau), the given conversion coefficient needs to be considered for more accurate estimation.

\section{Conclusions}

We used data from 65 sites to explore the storage, distribution, and environmental controls of litter standing crop carbon in the shrublands of the Tibetan Plateau. The litter standing crop carbon was $10.93 \mathrm{Tg} C$ in the shrublands of the plateau. Most of the litter standing crop was stored in the branch standing crop, which accounted for $80 \%$ of all litter standing crop. The conversion coefficient was 0.44 for litter standing crop to litter standing crop carbon. Spatially, the litter standing crop showed a decreasing trend with increasing longitude, and was stable with latitude. Litter standing crop carbon decreased with increasing MAP, but MAT and aboveground biomass have had positive effects on litter standing crop carbon in the shrublands on the Tibetan Plateau.

Supplementary Materials: The following are available online at http://www.mdpi.com/1999-4907/10/11/987/s1, Figure S1: Relationships among aboveground biomass, litter standing crop carbon, and climatic factors, (a) mean annual temperature (MAT), (b) mean annual precipitation (MAP); Figure S2: Relationships among longitude, (a) mean annual precipitation (MAP), (b) mean annual temperature (MAT).

Author Contributions: Conceptualization, G.Z. and X.N.; Methodology, G.Z., X.N.; Investigation, L.Y.; Writing-Original Draft Preparation X.N. and D.W.; Project Administration, G.Z.

Acknowledgments: We thank Wenzhu Song, Zebing Zhong, Hechun Liu, and Yi Ning for facilitating our field surveys on the Tibetan Plateau and laboratory assistance. This study is funded by the National Program on Basic Work Project of China (2015FY11030001-5), Qinghai Province Natural Science Fund Project (2019-ZJ-910), Qinghai Province International Exchange and Cooperation Project (2019-HZ-807) and Strategic Priority Research Program of CAS (XDA0505030304).

Conflicts of Interest: The authors declare no conflict of interest. The founding sponsors had no role in the design of the study; in the collection, analyses, or interpretation of data; in the writing of the manuscript and in the decision to publish the results.

\section{References}

1. Descheemaeker, K.; Muys, B.; Nyssen, J.; Poesen, J.; Raes, D.; Haile, M.; Deckers, J. Litter production and organic matter accumulation in exclosures of the Tigray highlands, Ethiopia. For. Ecol. Manag. 2006, 233, 21-35. [CrossRef]

2. Peng, S.; Liu, Q. The dynamicis of forest litter and its responses to global warming. Acta Ecol. Sin. 2002, 9, 1534-1544.

3. Bojko, O.; Kabała, C. Loss-on-ignition as an estimate of total organic carbon in the mountain soils. Pol. J. Soil Sci. 2014, 47, 71-79.

4. Pan, Y.; Birdsey, R.A.; Fang, J.; Houghton, R.; Kauppi, P.E.; Kurz, W.A.; Phillips, O.L.; Shvidenko, A.; Lewis, S.L.; Canadell, J.G. A large and persistent carbon sink in the world's forests. Science 2011, 333, 988-993. [CrossRef] [PubMed]

5. Wen, D.; He, N. Spatial patterns of litter density and their controlling factors in forests and grasslands of China. Acta Ecol. Sin. 2016, 36, 2876-2884.

6. Marty, C.; Houle, D.; Gagnon, C. Variation in stocks and distribution of organic C in soils across 21 eastern Canadian temperate and boreal forests. Forest Ecol. Manag. 2015, 345, 29-38. [CrossRef]

7. Domke, G.M.; Perry, C.H.; Walters, B.F.; Woodall, C.W.; Russell, M.B.; Smith, J.E. Estimating litter carbon stocks on forest land in the United States. Sci. Total Environ. 2016, 557, 469-478. [CrossRef]

8. Liu, L.; Shen, G.; Chen, F.; Luo, L.; Xie, Z.; Yu, J. Dynamic characteristics of litterfall and nutrient return of four typical forests along the altitude gradients in Mt. Shennongjia, China. Acta Ecol. Sin. 2012, 32, 2142-2149. [CrossRef]

9. McLaren, J.R.; Buckeridge, K.M.; Weg, M.J.; Shaver, G.R.; Schimel, J.P.; Gough, L. Shrub encroachment in Arctic tundra: Betula nana effects on above-and belowground litter decomposition. Ecology 2017, 98, 1361-1376. [CrossRef] 
10. Yang, Y. Ecological processes in alpine ecosystems under changing environment. Chin. J. Plant Ecol. 2018, 42, $1-5$.

11. Taylor, P.G.; Cleveland, C.C.; Wieder, W.R.; Sullivan, B.W.; Doughty, C.E.; Dobrowski, S.Z.; Townsend, A.R. Temperature and rainfall interact to control carbon cycling in tropical forests. Ecol. Lett. 2017, 20, 779-788. [CrossRef] [PubMed]

12. Wohl, E.; Barros, A.; Brunsell, N.; Chappell, N.A.; Coe, M.; Giambelluca, T.; Goldsmith, S.; Harmon, R.; Hendrickx, J.M.; Juvik, J. The hydrology of the humid tropics. Nat. Clim. Chang. 2012, 2, 655. [CrossRef]

13. Jia, B.; Zhou, G.; Liu, Y.; Jiang, Y. Spatial pattern and environment controls of annual litterfall production in natural forest ecosystems in China. Sci. Sin. Vitae 2016, 11, 1304-1311.

14. Zhao, Y.; Wang, X.; Zhang, Y. Relationship between litterfall production and meteorological factors in evergreen broad-leaved forest in Tiantong national forest park. J. Beijing Univ. Agric. 2017, 32, 73-77.

15. Zhang, X.; Wang, X.; Zhu, B.; Zong, Z.; Peng, C.; Fang, J. Litter fall production in relation to environmental factions in northeast China's forests. Chin. J. Plant Ecol. 2008, 32, 1031-1040.

16. Ge, J.; Xiong, G.; Li, J.; Xu, W.; Zhao, C.; Lu, Z.; Li, Y.; Xie, Z. 2017 Litter standing crop of shrubland ecosytem in southern China. Chin. J. Plant Ecol. 2017, 41, 5-13.

17. Hu, H.; Wang, Z.; Liu, G.; Fu, B. Vegetation carbon storage of Major shrublands in China. Chin. J. Plant Ecol. 2006, 30, 539-544.

18. Chen, S.; Liu, H.; Guo, D. Litter stocks and chemical quality of natural birch forests along temperature and precipitatioan gradients in eastern Inner Mongolia China. Chin. J. Plant Ecol. 2010, 34, 1007-1015.

19. Nie, X.; Yang, Y.; Yang, L.; Zhou, G. Above- and Belowground Biomass Allocation in Shrub Biomes across the Northeast Tibetan Plateau. PLoS ONE 2016, 11, e0154251. [CrossRef]

20. Nie, X.; Peng, Y.; Li, F.; Yang, L.; Xiong, F.; Li, C.; Zhou, G. Distribution and controlling factors of soil organic carbon storage in the northeast Tibetan shrublands. J. Soils Sediments 2019, 19, 322-331. [CrossRef]

21. Nie, X.; Yang, L.; Li, F.; Xiong, F.; Li, C.; Zhou, G. Storage, patterns and controls of soil organic carbon in the alpine shrubland in the Three Rivers Source Region on the Qinghai-Tibetan Plateau. Catena 2019, 178, 154-162. [CrossRef]

22. Yang, Y.; Fang, J.; Tang, Y.; Ji, C.; Zheng, C.; He, J.; Zhu, B. Storage, patterns and controls of soil organic carbon in the Tibetan grasslands. Glob. Chang. Biol. 2008, 14, 1592-1599. [CrossRef]

23. Zhou, X.; Wang, Z.B.; Du, Q. Vegetation of Qinghai Province; Qinghai People's Publishing House: Xining, China, 1987; pp. 53-72.

24. Wu, Z. Vegetation of China; Science Press: Beijing, China, 1980; p. 430.

25. Zhang, Z. Geography of Qinghai Plateau; Science Press: Beijing, China, 2009; pp. 25-26.

26. Chinese Academy of Science. Vegetation Altas of China; Science Press: Beijing, China, 2001.

27. Technical Manual Writing Group of Ecosystem Carbon Sequestration Project. Observation and Investigation for Carbon Sequestration in Terrestrial Ecosystems; Science Press: Beijing, China, 2015; pp. 153-155.

28. Yang, X.; Tang, Z.; Ji, C.; Liu, H.; Ma, W.; Mohhamot, A.; Shi, Z.; Sun, W.; Wang, T.; Wang, X.; et al. Scaling of nitrogen and phosphorus across plant organs in shrubland biomes across Northern China. Sci. Rep. 2014, 4, 5448. [CrossRef] [PubMed]

29. Nie, X.; Xiong, F.; Yang, L.; Li, C.; Zhou, G. Soil nitrogen storage, distribution, and associated controlling factors in the northeast Tibetan Plateau shrublands. Forests 2017, 8, 416. [CrossRef]

30. He, H. Modeling Forest NPP Patterns on the Tibetan Plateau and Its Responses to Cliamte Change; Chinese Academy of Forestry: Beijing, China, 2008.

31. Yang, Y. Carbon and Nitrogen in Alpine Grasslands on the Tibetan Plateau. Ph.D. Thesis, Peking University, Beijing, China, 2008.

32. Li, J. Biodiversity and Its Relationship to Ecosystem Production in Shrubland across Subtropical Region in China. Ph.D. Thesis, Institute of Botany, Chinese Academy of Sciences, Beijing, China, 2015.

33. Zhou, X.; Talley, M.; Luo, Y. Biomass, litter, and soil respiration along a precipitation gradient in southern Great Plains, USA. Ecosystems 2009, 12, 1369-1380. [CrossRef]

34. Chave, J.; Navarrete, D.; Almeida, S.; Alvarez, E.; Aragão, L.E.; Bonal, D.; Châtelet, P.; Silva-Espejo, J.; Goret, J.Y.; Hildebrand, P. Regional and seasonal patterns of litterfall in tropical South America. Biogeosciences 2010, 1, 43-55. [CrossRef] 
35. Wynn, J.G.; Bird, M.I.; Vellen, L.; Grand-Clement, E.; Carter, J.; Berry, S.L. Continental-scale measurement of the soil organic carbon pool with climatic, edaphic, and biotic controls. Glob. Biogeochem. Cycles 2006, 20, GB1007. [CrossRef]

36. Wieder, W.R.; Cleveland, C.C.; Townsend, A.R. Controls over leaf litter decomposition in wet tropical forests. Ecology 2009, 90, 3333-3341. [CrossRef]

37. Hilli, S.; Stark, S.; Derome, J. Litter decomposition rates in relation to litter stocks in boreal coniferous forests along climatic and soil fertility gradients. Appl. Soil Ecol. 2010, 46, 200-208. [CrossRef]

38. Hobbie, S.E. Temperature and plant species control over litter decomposition in Alaskan tundra. Ecol. Monogr. 1996, 66, 503-522. [CrossRef]

39. Fierer, N.; Craine, J.M.; McLauchlan, K.; Schimel, J.P. Litter quality and the temprtature sensitivity of decomposition. Ecology 2005, 86, 320-326. [CrossRef]

40. Nie, X.; Yang, L.; Xiong, F.; Li, C.; Fan, L.; Zhou, G. Aboveground biomass of the alpine shrub ecosystems in Three-River Source Region of the Tibetan Plateau. J. Mt. Sci. 2018, 15, 357-363. [CrossRef]

41. Duan, K.; Yao, T.; Wang, K.; Tian, L.; Xu, B. The Difference in precipitation variabil ity between the north and south Tibetan Plateaus. J. Glaciol. Geocryol. 2008, 30, 726-732.

42. Ding, J.; Li, F.; Yang, G.; Chen, L.; Zhang, B.; Liu, L.; Fang, K.; Qin, S.; Chen, Y.; Peng, Y.; et al. The permafrost carbon inventory on the Tibetan Plateau: A new evaluation using deep sediment cores. Glob. Chang. Biol. 2016, 22, 2688-2701. [CrossRef] [PubMed]

43. Cleveland, C.C.; Wieder, W.R.; Reed, S.C.; Townsend, A.R. Experimental drought in a tropical rain forest increases soil carbon dioxide losses to the atmosphere. Ecology 2010, 91, 2313-2323. [CrossRef] [PubMed]

44. Vergutz, L.; Manzoni, S.; Porporato, A.; Novais, R.F.; Jackson, R.B. Global resorption efficiencies and concentrations of carbon and nutrients in leaves of terrestrial plants. Ecol. Monogr. 2012, 82, 205-220. [CrossRef]

45. Schreeg, L.A.; Mack, M.C.; Turner, B.L. Nutrient-specific solubility patterns of leaf litter across 41 lowland tropical woody species. Ecology 2013, 94, 94-105. [CrossRef]

46. Sun, X.; Kang, H.; Chen, H.; Berg, B.; Bartels, S.F.; Liu, C. Biogeographic patterns of nutrient resorption from Quercus variabilis Blume leaves across China. Plant Biol. 2016, 18, 505-513. [CrossRef]

47. Fang, J.; Chen, A.; Peng, C.; Zhao, S.; Ci, L. Changes in forest biomass carbon storage in China between 1949 and 1998. Science 2001, 292, 2320-2322. [CrossRef] [PubMed]

48. Guo, Z.; Hu, H.; Li, P.; Li, N.; Fang, J. Spatio-temporal changes in biomass carbon sinks in China's forests from 1977 to 2008. Sci. China Life Sci. 2013, 56, 661-671. [CrossRef]

49. Piao, S.; Fang, J.; Zhou, L.; Tan, K.; Tao, S. Changes in biomass carbon stocks in China's grasslands between 1982 and 1999. Glob. Biogeochem. Cycles 2007, 21, GB2002. [CrossRef]

50. Ma, W.; Fang, J.; Yang, Y.; Mohammat, A. Biomass carbon stocks and their changes in northern China's grasslands during 1982-2006. Sci. China Life Sci. 2010, 53, 841-850. [CrossRef] [PubMed] 